\title{
Microbial gene functions enriched in the Deepwater Horizon deep-sea oil plume
}

\author{
Zhenmei $\mathrm{Lu}^{1,2}$, Ye Deng ${ }^{2}$, Joy D Van Nostrand ${ }^{2}$, Zhili $\mathrm{He}^{2}$, James Voordeckers ${ }^{2}$, \\ Aifen Zhou ${ }^{2}$, Yong-Jin Lee ${ }^{2}$, Olivia U Mason ${ }^{3}$, Eric A Dubinsky ${ }^{3}$, Krystle L Chavarria ${ }^{3}$, \\ Lauren M Tom ${ }^{3}$, Julian L Fortney ${ }^{3}$, Regina Lamendella ${ }^{3}$, Janet K Jansson ${ }^{3}$, \\ Patrik D’haeseleer ${ }^{3}$, Terry C Hazen ${ }^{3}$ and Jizhong Zhou ${ }^{2,3,4}$ \\ ${ }^{1}$ College of Life Sciences, Zhejiang University, Hangzhou, China; ${ }^{2}$ Department of Botany and Microbiology, \\ Institute for Environmental Genomics, University of Oklahoma, Norman, OK, USA; ${ }^{3}$ Earth Sciences Division, \\ Lawrence Berkeley National Laboratory, Berkeley, CA, USA and ${ }^{4}$ Department of Environmental Science and \\ Engineering, Tsinghua University, Beijing, China
}

\begin{abstract}
The Deepwater Horizon oil spill in the Gulf of Mexico is the deepest and largest offshore spill in the United State history and its impacts on marine ecosystems are largely unknown. Here, we showed that the microbial community functional composition and structure were dramatically altered in a deep-sea oil plume resulting from the spill. A variety of metabolic genes involved in both aerobic and anaerobic hydrocarbon degradation were highly enriched in the plume compared with outside the plume, indicating a great potential for intrinsic bioremediation or natural attenuation in the deep sea. Various other microbial functional genes that are relevant to carbon, nitrogen, phosphorus, sulfur and iron cycling, metal resistance and bacteriophage replication were also enriched in the plume. Together, these results suggest that the indigenous marine microbial communities could have a significant role in biodegradation of oil spills in deep-sea environments.

The ISME Journal (2012) 6, 451-460; doi:10.1038/ismej.2011.91; published online 4 August 2011
\end{abstract}

Subject Category: microbial ecology and functional diversity of natural habitats

Keywords: oil spill; deep-sea plume; microbial community; metagenomics; functional gene arrays; GeoChip

\section{Introduction}

On 20 April 2010, a massive oil leak occurred in the Gulf of Mexico's Mississippi Canyon area at a depth of $1544 \mathrm{~m}$, releasing $\sim 4.9$ million barrels of crude oil into the deep ocean before the wellhead was finally capped on 15 July 2010 (The Federal Interagency Solutions Group, Oil Budget Calculator Science and Engineering Team, November 2010). Chemical dispersants, including COREXIT EC9500A and COREXIT EC9527A, were used on site at one of the highest rates in history to accelerate oil dispersal. A deep-water oil plume was initially detected at a depth of $1000-1200 \mathrm{~m}$ below the surface (Camilli et al., 2010; Hazen et al., 2010; Mascarelli, 2010a), but at last account (Mascarelli, $2010 \mathrm{~b}$ ) could no longer be detected, presumably as a result of dispersion and microbial degradation (OSAT, 2010). Significant environmental differences in the deep sea of Gulf of Mexico from other historic

Correspondence: J Zhou, Department of Botany and Microbiology, Institute for Environmental Genomics, University of Oklahoma, Norman, OK 73019, USA.

E-mail: jzhou@ou.edu

Received 3 March 2011; revised 6 June 2011; accepted 6 June 2011; published online 4 August 2011 offshore oil spills present an urgent need to better understand the fate and impacts of the oil on this specific habitat (Kerr et al., 2010a,b).

In marine ecosystems, microorganisms are known to have predominant roles in degradation of oil contaminants (Head et al., 2003; Larter et al., 2003). Therefore, it was expected that the indigenous microbial communities would have a significant role in degradation of the deep oil plume. This hypothesis was supported by two recent studies that explored the microbial and chemical properties of samples collected from the deep oil plume (Camilli et al., 2010; Hazen et al., 2010). Hazen et al. (2010) used a combination of molecular, chemical and physiological approaches to investigate the microbial and chemical composition in the deep-sea plume compared with uncontaminated water from the same depth outside the plume. They demonstrated that the oil depletion was due to a combination of mixing, dispersion and biodegradation by microbes residing in the deep sea (Hazen et al., 2010).

In this study, samples from the deep-sea plume, oil-contaminated seawater (hereafter referred to as 'oil plume' in the following text) and non-plume controls (seawater samples at same depth that were not contaminated with oil) were analyzed with a functional gene microarray, the GeoChip 4.0 
(Hazen et al., 2010), to address the following questions: (i) How did the oil contamination affect the marine microbial community functional composition and structure? (ii) How did different microbial functional genes involved in key microbial processes shift in response to the oil spill? (iii) Were functional genes specific to hydrocarbon (HC) degradation processes enriched in the oil plume? Our results indicated that the oil spill dramatically altered microbial community functional structure, the marine microbial communities present were metabolically diverse, and that these communities were able to respond to the oil spill.

\section{Materials and methods}

The following is the summary of methods used in this study. More detailed information is provided in Supplementary Data A.

\section{Sample description}

Between 27 May and 2 June 2010, seawater samples were collected from the Gulf of Mexico during two monitoring cruises on the R/V Ocean Veritas and R/ V Brooks McCall (Supplementary Table S1) as previously described (Hazen et al., 2010). Briefly, two colored dissolved organic matter WETstar fluorometers (WET Labs, Philomath, OR, USA) were attached to a CTD sampling rosette (Sea-Bird Electronics Inc., Bellevue, WA, USA) and used to detect the presence of oil. The fluorometer results were subsequently confirmed by laboratory HC analysis. Niskin bottles attached to the CTD rosette were used to capture water samples at various depths with detected HCs. Eight samples (BM053, BM054, BM057, BM058, BM064, OV201, OV401 and OV501) from the MC252 dispersed oil plume, and five samples (OV003, OV004, OV009, OV013 and OV014) from non-plume at a depth of 1099-1219 m were analyzed in this study.

To better define the geochemical properties of the plume and non-plume samples, two sets of variables were measured: (i) seawater variables (dissolved oxygen, temperature, small particle counts, total ammonia nitrogen, nitrite $\left(\mathrm{NO}_{2}-\mathrm{N}\right)$, total iron), orthophosphate $\left(\mathrm{PO}_{4}-\mathrm{P}\right)$ and acridine orange direct count) and (ii) oil composition variables (fluorometer detection of oil, benzene, toluene, ethylbenzene, isopropylbenzene, $n$-propylbenzene, $1,3,5$-trimethylbenzene, tert-butylbenzene, 1,2,4-trimethylbenzene, sec-butylbenzene, $p$-isopropyltoluene, n-butylbenzene, naphthalene and $o$-xylene, $m$ - and $p$-xylenes) (Hazen et al., 2010).

\section{DNA amplification and labeling}

Approximately $100 \mathrm{ng}$ of DNA that was previously extracted from the samples (Hazen et al., 2010) was amplified using a modification of the Templiphi kit (GE Healthcare, Piscataway, NJ, USA). The amplified DNA $(2 \mu \mathrm{g})$ was then labeled with Cy3 using random primers and the Klenow fragment of DNA polymerase I (Wu et al., 2006) and then purified and dried in a SpeedVac $\left(45^{\circ} \mathrm{C}, 45 \mathrm{~min}\right.$; ThermoSavant, Milford, MA, USA) before hybridization.

\section{GeoChip 4.0 hybridization and data pre-processing} The GeoChip 4.0, containing 83992 50-mer oligonucleotide probes targeting 152414 genes in 410 gene categories for different microbial functional and biogeochemical processes, was synthesized by NimbleGen (Madison, WI, USA). All hybridizations were carried out at $42{ }^{\circ} \mathrm{C}$ with $40 \%$ formamide for $16 \mathrm{~h}$ on a MAUI hybridization station (BioMicro, Salt Lake City, UT, USA). After hybridization, the arrays were scanned (NimbleGen MS200, Madison, WI, USA) at a laser power of $100 \%$. Signal intensities were measured based on scanned images, and spots with signal-to-noise ratios lower than 2 were removed before statistical analysis as described previously (He et al., 2010).

\section{Statistical analysis}

Pre-processed GeoChip data were further analyzed with different statistical methods: (i) microbial diversity index, the two-tailed $t$-test and response ratio (Luo et al., 2006); (ii) hierarchical clustering for microbial community structure and composition (de Hoon et al., 2004); (iii) analysis of similarity, permutational multivariate analysis of variance using distance matrices and multiresponse permutation procedure analysis of differences of microbial communities (Anderson, 2001); (iv) canonical correspondence analysis (CCA) for linking microbial communities to environmental variables (Ramette and Tiedje, 2007; Zhou et al., 2008); and (v) partial CCA for co-variation analysis of wellhead distance and environmental variables (variation partitioning analysis). Details for all methods are provided in the Supplementary Information.

\section{Results}

Functional gene changes in response to oil spill

To assess the dynamic changes of microbial communities in response to oil spill, microbial community functional composition and structure were analyzed using functional gene arrays (GeoChip 4.0). Significantly more functional genes $(P<0.01)$ were detected in the oil plume samples than in nonplume control (Supplementary Table S2). The overall microbial functional diversity was also significantly $(P<0.01)$ higher in the plume samples based on Shannon-Weiner $\left(H^{\prime}\right)$ and Simpson's $(1 / D)$ indices. Consistent with geochemical ordination patterns, hierarchical clustering analysis showed that all plume samples were clustered together and well separated from non-plume samples (Figure 1 

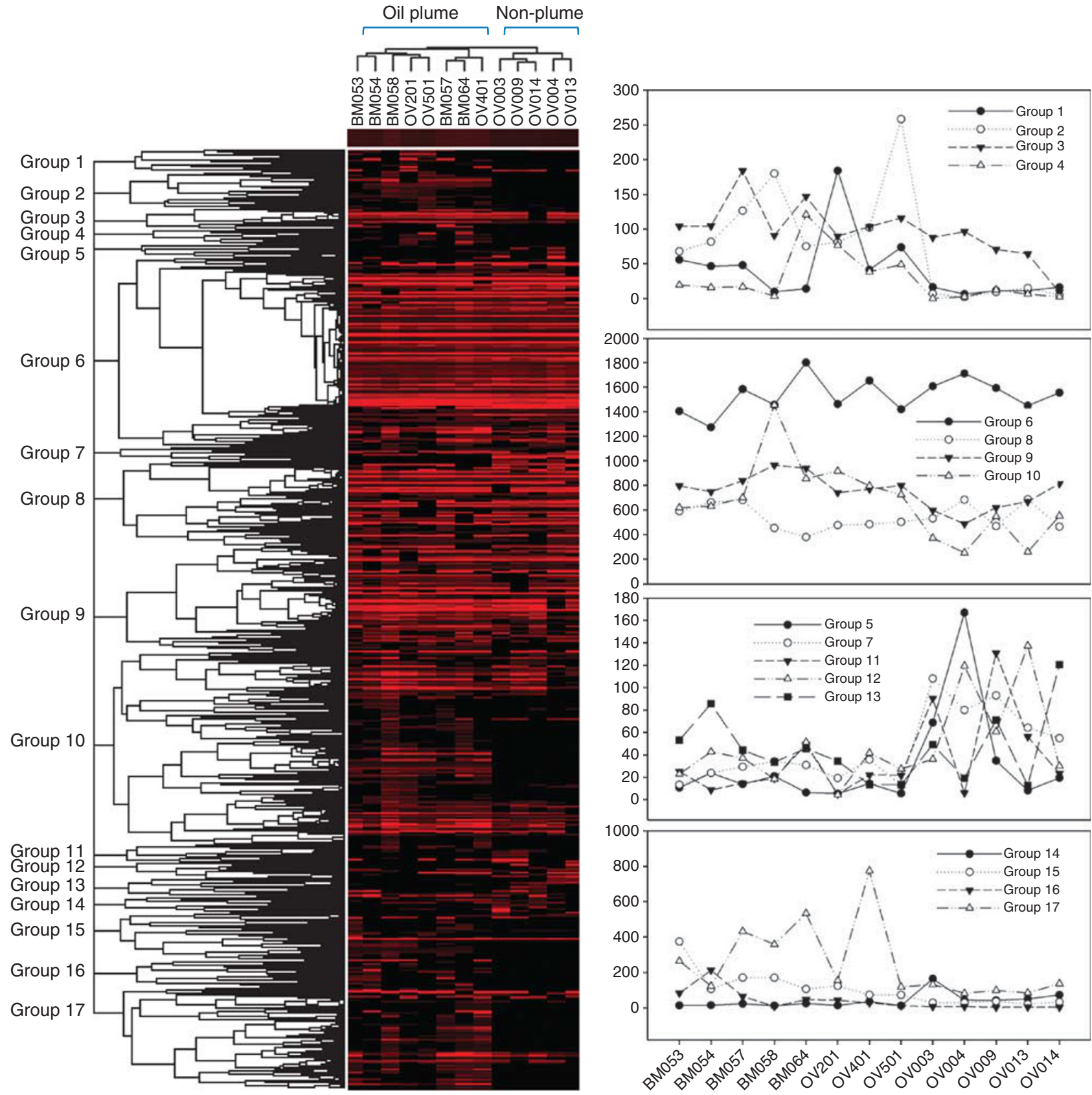

Figure 1 Hierarchical cluster analysis of all genes present in at least two out of the five samples. Results were generated in CLUSTER and visualized using TREEVIEW. Red indicates signal intensities above background, whereas black indicates signal intensities below background. Brighter red coloring indicates higher signal intensities. All oil plume samples clustered together and were well separated from non-plume samples.

and Supplementary Figure S1), as also shown for the microbial communities at a phylogenetic level (Hazen et al., 2010). However, considerable variability in functional gene distribution was observed among different samples and some functional genes were common to all samples, although others were unique to oil plume samples (Figure 1). For example, Group 6, with 1439 or $20.14 \%$ of all genes detected, largely involved in organic remediation, carbon degradation, denitrification, sulfate reduction, metal resistance and stress response, was generally detected in all samples. Groups 1, 2, 10 and 17 , with $2.2 \%, 3.9 \%, 20.5 \%$ and $10.8 \%$ of all genes detected, were mainly detected in the plume samples (Figure 1). In addition, the microbial community functional structure was significantly $(P<0.05)$ different between the plume and nonplume samples as revealed by the three complementary non-parametric multivariate statistical tests (analysis of similarity, permutational 
Table 1 Significance of the effects of the oil spill on the overall microbial community structure and geochemical pattern using three statistical analyses

\begin{tabular}{lrrrrr}
\hline \multirow{2}{*}{ Method } & \multicolumn{2}{c}{ Geochemical parameters $^{\mathrm{a}}$} & & \multicolumn{2}{c}{ Microbial community } \\
\cline { 2 - 3 } \cline { 6 - 6 } \cline { 5 - 6 } & Statistic & P-value & & Statistic & P-value \\
\hline MRPP $^{\mathrm{b}}$ & 233.112 & 0.037 & & 53.617 & 0.003 \\
ANOSIM $^{\mathrm{c}}$ & 0.057 & 0.046 & & 0.501 & 0.002 \\
Adonis $^{\mathrm{d}}$ & 0.258 & 0.043 & & 0.192 & $<0.001$ \\
\hline
\end{tabular}

Abbreviations: ANOSIM, analysis of similarity; MRPP, multi response permutation procedure.

${ }^{a}$ Geochemical parameters included temperature, DO concentration, fluorometer detection of oil, small particle concentrations, Fe, nitrate, phosphate, benzene, toluene, naphthalene, ethylbenzene, isopropylbenzene, $n$-propylbenzene, 1,3,5-trimethylbenzene, tert-butylbenzene, 1,2,4-trimethylbenzene, sec-butylbenzene, $p$-isopropyltoluene, $n$-butylbenzene, total xylenes, total volatile HC and total petroleum hydrocarbons-extractable (DRO).

${ }^{b}$ Multiple response permutation procedure, a nonparametric procedure that does not depend on assumptions such as normally distributed data or homogeneous variances, but rather depends on the internal variability of the data.

${ }^{\mathrm{c}}$ Analysis of similarities.

${ }^{\mathrm{d} N o n-p a r a m e t r i c ~ m u l t i v a r i a t e}$ analysis of variance (MANOVA) with the adonis function.

All three tests are non-parametric multivariate analyses based on dissimilarities among samples.

multivariate analysis of variance using distance matrices and multiresponse permutation procedure) (Table 1).

Oil as a predominant factor shaping microbial community functional structure

CCA was performed to determine the most significant environmental variables shaping microbial community structure. On the basis of variance in inflation factors, seven variables were selected: dissolved oxygen, temperature, total volatile HC, total extractable petroleum HC, fluorometer detection of oil, phosphate and iron. The specified CCA model was significant $(P=0.026)$. Of these, the total volatile HC, extractable petroleum HC, fluorometer detection of oil and dissolved oxygen were the most significantly correlated with plume samples (Figure 2). To separate the effects of seawater geochemical variables, geographic distance and oil composition on microbial community structure, a CCA-based variation partitioning analysis (Ramette and Tiedje, 2007; Zhou et al., 2008) was performed. Seawater geochemical variables, oil composition and wellhead distance showed a significant correlation $(P=0.041)$ with the functional gene structure of the community. Oil composition explained substantially more variations $(48.34 \%, P=0.03)$ than seawater variables $(21.76 \%, P=0.017)$, whereas distance independently explained $9.1 \%(P=0.43)$ of the observed variation (Figure 3 ). About $28 \%$ of the community functional variation based on GeoChip data remained unexplained by the above selected variables, which is significantly lower than those observed in other systems such as soils

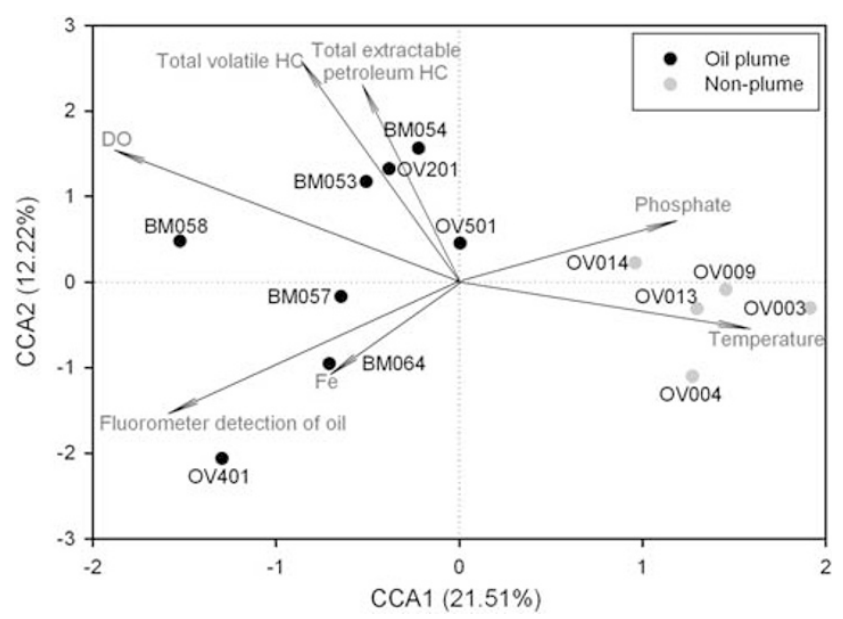

Figure 2 CCA compares the GeoChip hybridization signal intensities (symbols) and environmental variables (arrows). Environmental variables were chosen based on significance calculated from individual CCA results and variance inflation factors (VIFs) calculated during CCA. The percentage of variation explained by each axis is shown, and the relationship is significant $(P=0.026)$.
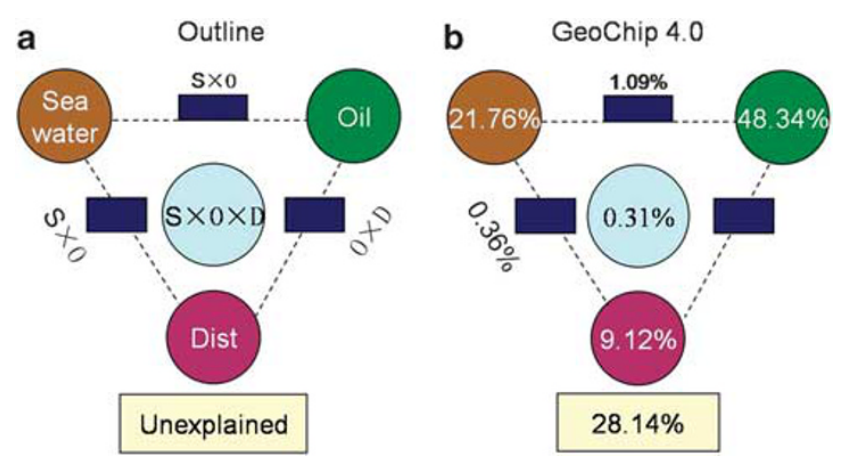

Figure 3 Variation partitioning based on CCA for all functional gene signal intensities. (a) General outline, (b) all functional genes. A CCA-based VIF was performed to identify common sets of oil composition and seawater variables important to the microbial community structure. Oil composition variables included fluorometer detection of oil, the concentration of total volatile HCs, xylenes and petroleum HCs-extractable (DRO). Seawater geochemical variables included temperature, dissolved oxygen (DO), Fe and phosphate.

(Ramette and Tiedje, 2007; Zhou et al., 2008). These results indicate that oil contaminants could be a dominant factor shaping microbial community functional structure and potentially regulating associated microbial functional processes.

\section{Oil spill stimulated increase in functional genes for HC degradation}

A substantial number of genes involved in $\mathrm{HC}$ degradation were detected in the oil plume samples (Hazen et al., 2010), especially those involved in degrading alkanes, alkynes and cycloalkanes, BTEX and related aromatics, chlorinated aromatics, heterocyclic aromatics, nitroaromatics, polycyclic aromatics and aromatic carboxylic acids. For 


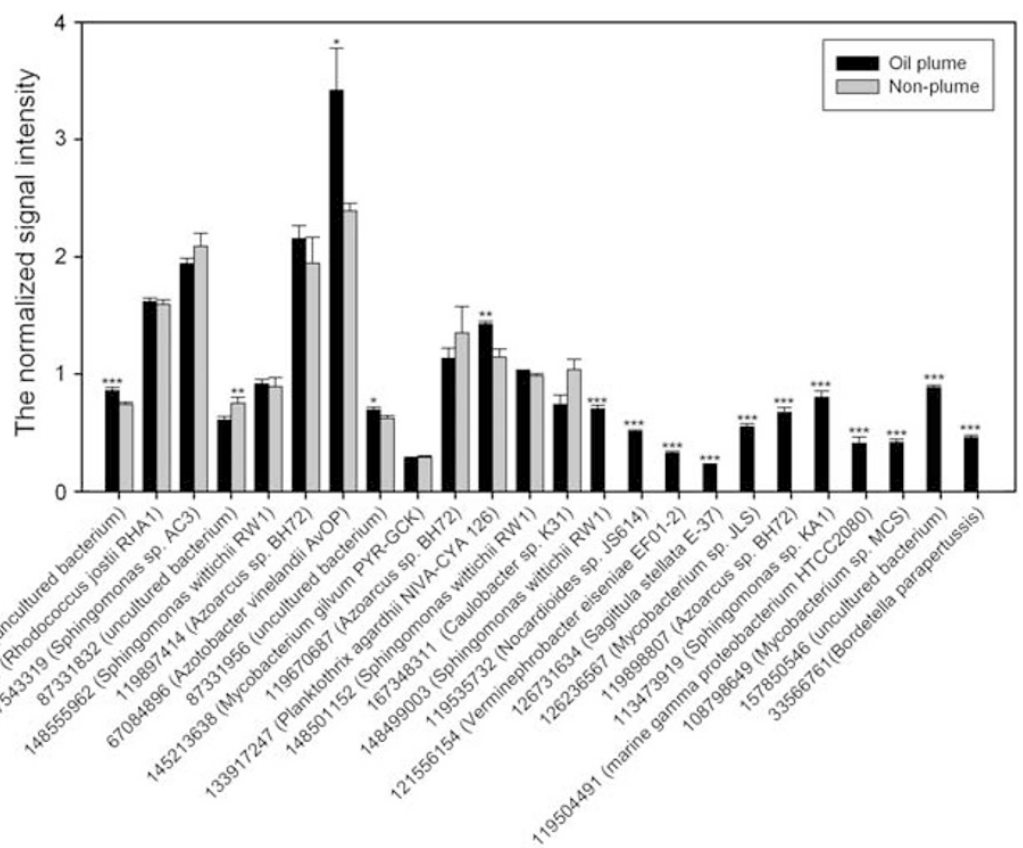

Figure 4 The normalized signal intensity of the nahA genes (naphthalene 1,2-dioxygenase) for the initial oxidation of naphthalene. The signal intensity for each sequence was the average of the total signal intensity from all the replicates. Gene number is the protein ID number for each gene as listed in the GenBank database. All data are presented as mean \pm s.e. ${ }^{* *} P<0.01,{ }^{*} P<0.05$, ${ }^{*} P<0$. 1 .

example, gene alkB encoding alkane 1-monooxygenase, a key enzyme responsible for the initial oxidation of inactivated alkanes, showed a significantly $(P<0.05)$ higher abundance, with 19-26 genes detected in the oil contaminated samples and 11-15 detected in the non-oil contaminated samples. The alkB genes derived from Rhodospirillum centenum SW, Bdellovibrio bacteriovorus HD100, Prauserella rugosa, Roseobacter sp. CCS2, Mycobacterium bovis AF2122/97, Bacillus sp. BTRH40, Gordonia sp. $\mathrm{Cg}$ and Rhodococcus sp. RHA1 appeared to be dominant in all oil plume samples (Supplementary Figure S2).

GeoChip analysis also detected many aerobic PAH degradation genes from a variety of microorganisms (Figure 4 and Supplementary Figure S3). PAH degradation genes were more abundant in the plume samples, while some were unique to the plume samples. Although oxygen was still present in the plume samples (Camilli et al., 2010; Hazen et al., 2010), the gene bbs (beta-oxidation of benzylsuccinate) for anaerobic toluene degradation was also enriched in plume samples. These bbs genes were derived from putative E-phenylitaconyl-CoA hydratase of Azoarcus sp. EbN1 and Thauera aromatic, and benzylsuccinyl-CoA dehydrogenase of Azoarcus sp. EbN1 (Figure 5).

Shifts of the genes involved in key biogeochemical cycling processes

Carbon. Among the carbon cycling genes detected, 798 genes involved in the degradation of complex

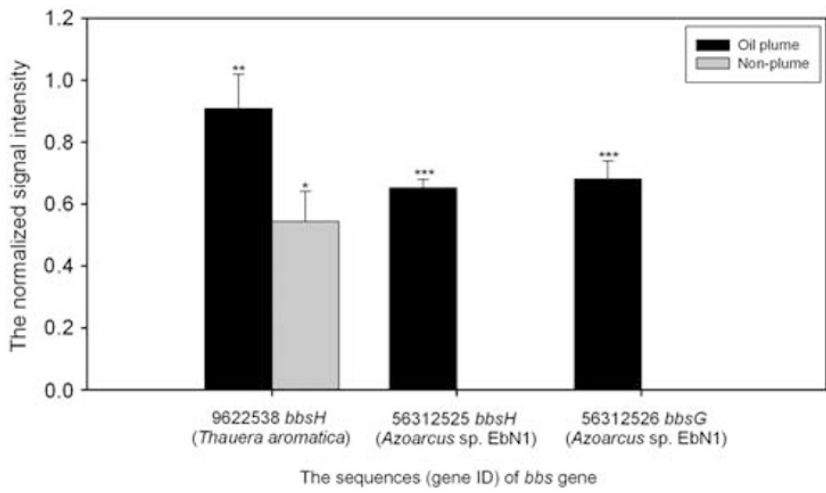

Figure 5 The normalized signal intensity of $b b s$ ( $\beta$-oxidation of benzylsuccinate) genes for anaerobic toluene degradation. The signal intensity for each sequence was the average of the total signal intensity from all the replicates. Gene number is the protein ID number for each gene as listed in the GenBank database. All data are presented as mean \pm s.e. ${ }^{* * *} P<0.01$, ${ }^{* *} P<0.05,{ }^{*} P<0.1$. In total, seven probes were designed for bbs genes in GeoChip 4.0 and three probes were detected in the samples.

carbon compounds, such as starch, hemicellulose, cellulose, chitin, lignin and aromatics, showed positive hybridization signals. Most of these genes (for example, pulA, xylA, xynA, lip, limEH and van $A)$ showed significantly $(P<0.05)$ higher abundance in plume than in non-plume samples (Supplementary Figure S4). These types of genes could also be important in degradation of various oil components and their intermediates.

In this study, 9-14 morA genes encoding the $\alpha$ subunit of methyl coenzyme $M$ reductase and 5-8 
pmo $A$ genes for methane monooxygenase were detected in the plume samples. Specifically, mcrA genes from Methanococcus aeolicus Nankai-3, Methanoculleus marisnigri JR1 and Methanocorpusculum labreanum $\mathrm{Z}$ were detected in all of the oil plume samples, but most of them were from uncultured microorganisms. Significantly $(P<0.05)$ higher signal intensities were observed for mcrA in the plume than in the non-plume samples (Supplementary Figure S5). However, no significant differences were found for $p m o A$ and $\operatorname{mmoX}$ (particulate methane monooxygenase) between plume and nonplume samples.

Nitrogen. Petroleum generally contains about $0.1-2 \%$ nitrogen, and given the large quantities of oil involved, it may act as an $\mathrm{N}$ pool in this ecosystem. Interestingly, nas $A$ (nitrate reductase) and nir (nitrite reductase) for assimilatory $\mathrm{N}$ reduction, and gdh (glutamate dehydrogenase) for ammonia assimilation exhibited significantly $(P<0.05$ or 0.01) higher signal intensities in plume samples (Figure 6). The observed stimulation of $\mathrm{N}$ assimilation processes could be due to an increase of microbial biomass (Hazen et al., 2010). However, no significant differences were observed for other $\mathrm{N}$-cycling genes, for example, nitrification, denitrification and $\mathrm{N}$ fixation (Figure 6).

Sulfur. Sulfite reduction genes were highly abundant in the deep-sea plume: 81-102 $d s r A / B$ genes for dissimilatory sulfite reductase, and 8-12 AprA genes for dissimilatory adenosine-5'-phosphosulfate reductase were detected with significantly $(P<0.05)$ higher abundance in the plume than in non-plume samples (Supplementary Figure S6). Microbial populations similar to Alkalilimnicola ehrlichei MLHE-1, Chlorobium ferrooxidans DSM 13031, Clostridium leptum DSM 753, Desulfomicrobium thermophilum, Pyrobaculum calidifontis JCM 11548, Thermodesulforhabdus norvegica, Magnetococcus sp. MC-1, Pyrobaculum aerophilum str. IM2, Alkalilimnicola ehrlichei MLHE-1, Desulfohalobium retbaense DSM 5692, sulfate-reducing bacterium QLNR1 and Syntrophobacter fumaroxidans MPOB were frequently detected in each sample, while most of the genes detected were from uncultured microorganisms (for example, sulfate-reducing bacteria) from various environments. The results suggest that sulfate reduction could be enhanced when coupled with HC degradation.

Phosphorus and iron reduction. As phosphorus is often a limiting factor for oil bioremediation, it is essential to understand phosphorus cycling in marine ecosystems. Genes encoding exopolyphosphatase $(p p x)$ for inorganic polyphosphate degradation and phytase for phytate degradation were detected with significantly $(P<0.01$ and $P<0.05$, respectively) increased abundance in plume samples (Supplementary Figure S7). These results

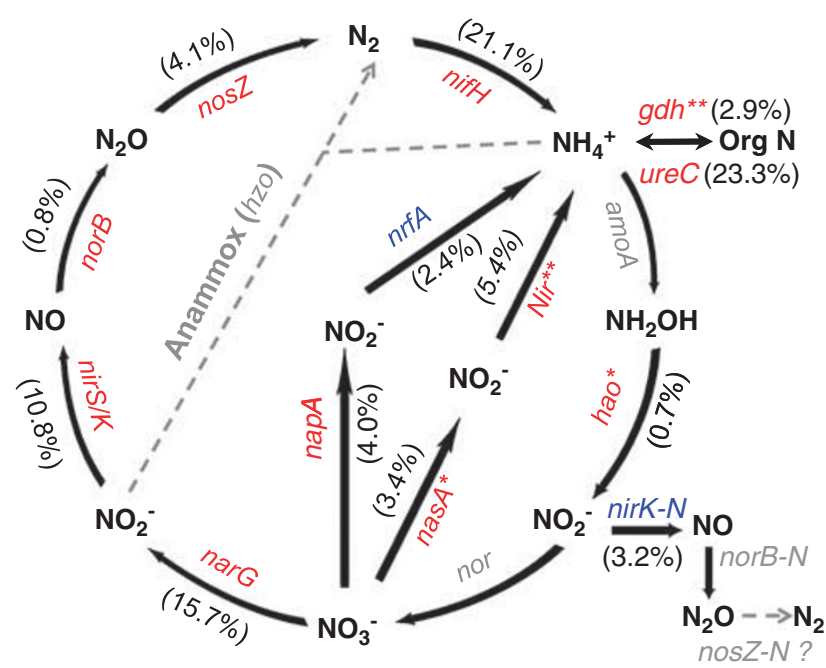

Figure 6 The relative changes of the detected genes involved in the $\mathrm{N}$ cycle in oil plume. The signal intensity for each gene detected was normalized by all detected gene sequences using the mean. The percentage of a functional gene in a bracket was the sum of signal intensity of all detected sequences of this gene divided by the grand sum of signal intensity of the detected $\mathrm{N}$ cycle genes, and weighted by the fold change of the signal intensity of this gene in plume to that in non-plume. For each functional gene, red indicates that this gene had a higher signal intensity in plume than in non-plume and their significance was indicated with two stars $\left({ }^{* *}\right)$ at $P<0.01$, whereas blue indicates that this gene had a lower signal intensity in oil-plume than in non-plume. Grey-colored genes were not targeted by this GeoChip, or not detected in those samples. It remains unknown if nosZ homologs exist in nitrifiers. Description of the genes: (a) gdh, encoding glutamate dehydrogenase, ureC, encoding urease responsible for ammonification; (b) nas A, encoding nitrate reductase, NiR, encoding nitrite reductase, responsible for assimilatory $\mathrm{N}$ reduction; (c) nifH, encoding nitrogenase responsible for $\mathrm{N}_{2}$ fixation; (d) narG encoding nitrate reductase, nirS and nirK- $D$ (with denitrification activity), encoding nitrite reductase; $n o s Z$, encoding nitrous oxide reductase, nor $B$, encoding nitric oxide reducatse, responsible for denitrification (e) napA, encoding periplasmic nitrate reductase, $n r f A$, encoding c-type cytochrome nitrite reducatse, responsible for dissimilatory $\mathrm{N}$ reduction to ammonium; (f) hao, encoding hydroxylamine oxidoreductase, and nirK- $N$ encoding nitrite reductase for nitrifiers (an indication of nitrification activity), responsible for nitrification.

suggested that organic phosphorus release could be stimulated by oil contamination. In addition, higher $(P<0.1)$ signal intensities for 61 detected cytochrome $c$ genes were observed in plume samples (Supplementary Figure S8), suggesting that HC degradation coupled with metal reduction could occur in the deep water.

Metal resistance. A substantial number (917) of the genes involved in resistance to various metals were detected, many of which showed significantly $(P<0.05)$ increased abundance in plume samples (Supplementary Figure S9). Genes encoding reductases for As (arsC) and $\mathrm{Hg}$ (mer), efflux transporters for $\mathrm{Cd}(\operatorname{cad} A), \mathrm{Cu}$, Co and $\mathrm{Zn}(\operatorname{czcA}$ and $c z c D), \mathrm{Cr}$ $(\mathrm{Chr} A), \mathrm{Cu}(\operatorname{cop} A), \mathrm{Hg}(\operatorname{mer} T), \mathrm{Ag}(\operatorname{sil} C)$ and $\mathrm{Zn}$ $(z n t A)$, and the proteins involved in Te resistance 


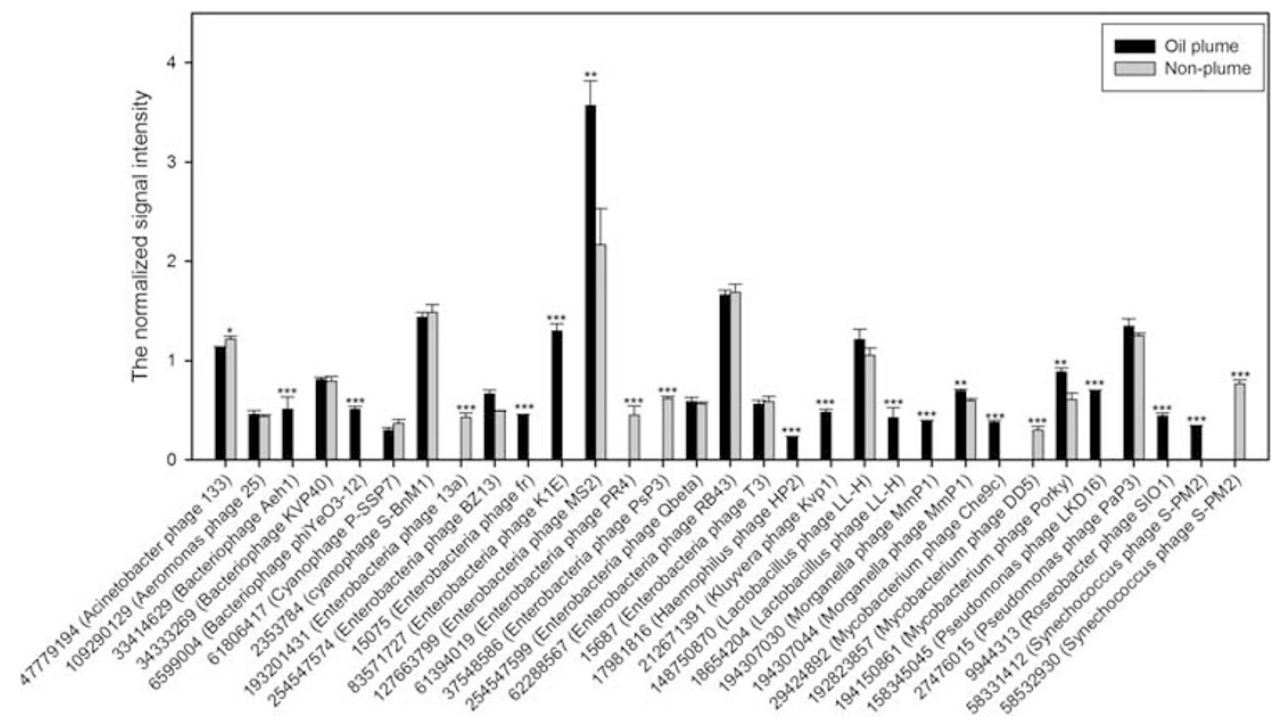

Figure 7 The normalized signal intensity of the replication genes for bacteriophage. The signal intensity for each sequence was the average of the total signal intensity from all the replicates. Gene number is the protein ID number for each gene as listed in the GenBank database. All data are presented as mean \pm s.e. ${ }^{* * *} P<0.01,{ }^{*} P<0.05,{ }^{*} P<0.1$.

(terC, terD and ter $Z$ ) were more $(P<0.05$ or 0.01$)$ abundant in the plume samples.

\section{Bacteriophages were also significantly stimulated} In total, 52 bacterial phage genes associated with host recognition, lysis, replication and structure were observed in all samples. The signal intensities for many of the genes involved in replication were significantly $(P<0.05)$ higher in the plume than in the non-plume samples (Figure 7), supporting the suggestion by Head et al. (2006) that bacteriophages could be an important factor for intrinsic bioremediation of HCs.

\section{Discussion}

The Deepwater Horizon oil spill in the Gulf of Mexico was one of the worst environmental disasters in the United State history. The impact of an oil spill of such an unprecedented magnitude and depth on marine ecosystems is largely unknown. Using the GeoChip-based high-throughput microarray technology, we showed that diverse microbial functional groups (a group of genes involved in certain functional processes), including those important to HC degradation, carbon metabolism, methanogenesis, nitrogen assimilation, sulfate reduction, phosphorus release, metal resistance and bacteriophage replication, were more highly represented in the oil plume samples than in non-plume samples from the same depth. Also, the changes in community functional structure were highly correlated to the changes in geochemistry, with oil being the predominant factor shaping the functional composition and structure of the microbial communities. Our results support the phylogenybased study by Hazen et al. (2010) that the deepsea marine microbial communities underwent a dynamic change in response to the oil spill and associated geochemical changes. Our results are also consistent with previous studies of oil spill and petroleum contamination (Harayama et al., 2004; Head et al., 2006; Bordenave et al., 2007), which showed that microorganisms able to utilize HCs became dominant in oil-contaminated sites. Such functional gene information is useful for assessing the impacts of oil spills and should facilitate the design of appropriate strategies and approaches to deal with petroleum contamination.

The clean-up of the deep-sea oil plume will primarily depend on the indigenous microbes present in this environment, as current technology does not allow removing the dispersed oil and gas at such great depths. One of the critical environmental questions is whether microorganisms for degrading various HCs exist in the community and whether they respond to oil spill. Our GeoChip results indicated that many functional genes/populations involved in both aerobic and anaerobic degradation of various oil components are detected and/or enriched in the oil plume, indicating that the indigenous HC-degrading populations are capable of responding to the oil spill. For example, alkB for alkanes, Xamo for alkene, genes bco, ohbAB, GCoADH and pimF for benzoate, genes mdlA, mdlB and $m d l C$ for mandelate, and genes $A p c$ and $c a t B$ for BTEX metabolic pathway exhibited a significantly $(P<0.05)$ higher abundance in the oil plume than in the non-oil plume. The changes in relative abundance of these genes/populations were significantly correlated with the concentrations of various oil contaminants in the samples (Hazen et al., 2010). 
Especially, several genes for PAH degradation were enriched in the oil plume samples, which could be important in determining the long-term effects of the oil spill on the marine ecosystems. Also, consistent with phylogenetic gene distribution obtained using a phylogenetic microarray 'PhyloChip' (Hazen et al., 2010), functional genes representative of the order Oceanospirillales appeared to have significantly higher $(P<0.01)$ abundance in the plume samples than in non-plume samples, although the dominance of the Oceanospirillum population consuming the oil in the plume was based on clone library and sequence analysis of $16 \mathrm{~S}$ rRNA genes (Hazen et al., 2010). GeoChip was not originally designed to link the detection of functional genes to the existence of related microbial population and it contains 567 functional genes derived from the order Oceanospirillales, with 25 genes detected in this study. In addition, a large number of metal resistance genes were enriched in plume samples, which are usually linked to organic degradation genes, for example, on plasmids (Parales and Haddock, 2004; Kunapuli et al., 2007). Our GeoChip results demonstrated that there is a great potential for intrinsic bioremediation of oil contamination in the deep-sea environment.

Anaerobic HC degradation associated with sulfate reduction, denitrification and methanogenesis has long been considered the prevailing mechanism for petroleum biodegradation in the deep subsurface (Head et al., 2003; Aitken et al., 2004; Kniemeyer et al., 2007; Jones et al., 2008). Recent investigations have demonstrated that several classes of petroleum HCs, including alkanes (So et al., 2003), mono- and polycyclic aromatic compounds (Meckenstock et al., 2000; Widdel and Rabus, 2001), and short-chain HCs (Kniemeyer et al., 2007), can be degraded anaerobically under nitrate-, iron- or sulfate-reducing conditions, or under methanogenic conditions (Harayama et al., 2004; Jones et al., 2008). Indeed, a substantial number of $d s r A / B$ genes for sulfate reduction, mcr $A$ genes for methanogenesis, narG, nirS, nirK and nosZ responsible for denitrification and populations for metal reduction were detected in this study. Also, $d s r A / B$ and mcrA genes showed significantly $(P<0.05$ or 0.01$)$ higher abundance in the plume than in the non-plume samples. In addition, $b b s$ genes for the strict anaerobic toluene degradation were detected and enriched in the plume samples. It is possible that anaerobic $\mathrm{HC}$ degradation could have most likely occured through microaggregate formation as reported in Hazen et al. (2010).

Hydrocarbon degradation is generally limited by nutrient availability, which can be improved by nutrient recycling through phage-mediated biomass turnover (Jiang et al., 1998; Head et al., 2006; Paul, 2008). As significant biomass increase was observed (Hazen et al., 2010) in the plume samples, bacteriophages could have critical roles in HC degradation. Approximately $43 \%$ of marine bacterial isolates have been found to contain prophages (Jiang et al., 1998; Paul, 2008), which are induced by various environmental contaminants, such as fuel oil (Cochran et al., 1998). The oil spill may stimulate the growth of pathogenic bacteria in marine environments and many pathogens are capable of efficiently degrading HCs (Rojo and Martínez, 2010). The research on phages has been heavily slanted to those that affect human-related activities, health/medical and industry. As no target genes for Oceanospirillum phages were designed on GeoChip 4.0, the Oceanospirillum phages were not detected. Genes for both iron uptake (iro) and adherence (pap and pilin) were significantly $(P<0.01$ or 0.05$)$ enriched in the plume samples. The increase in the abundance of microorganisms capable of producing siderophores, highly specific iron-chelating compounds, may facilitate microbial acquisition of iron, a limiting nutrient in marine systems (Barbeau et al., 2001a, b), thereby potentially increasing HC degradation.

A substantial quantity of methane gas was released together with the oil (The Federal Interagency Solutions Group, Oil Budget Calculator Science and Engineering Team, November 2010; Kessler et al., 2011), which may result in more methane in the oil plume ecosystem and have the potential to greatly impact methane metabolism. GeoChip targets three key genes/enzymes involved in methane metabolism, with mcrA encoding methyl coenzyme $M$ reductase for methanogenesis and two enzymes/genes (methane monooxygenase/ mmoX and particulate methane monooxygenase/ pmoA) for methanotrophy (He et al., 2010). In this study, $p m o A$ and $m m o X$ genes for aerobic methane oxidation did not show a statistically significant change though their abundance was higher in plume samples than in non-plume samples. There are two possible explanations for this: one is that the aerobic methane oxidation was inhibited owing to the presence of easier to degrade alkanes in the deep sea, and the other is that the methane gas was moved up to the surface more directly and did not accumulate in the deep oil plume. Also, unlike propane, methane may form gas hydrates at the deep plume temperature and pressure, making it unavailable to microorganisms (Valentine et al., 2010). However, significantly $(P<0.05)$ higher signal intensities were observed for mcrA in the plume than non-plume samples, indicating that those enriched $m c r A$ genes derived from methanogens likely link to HC degradation rather than plume methane release (Harayama et al., 2004; Jones et al., 2008). Enzymes or genes involved in anaerobic methane oxidation, however, remain unclear; thus, we could not detect this functional process.

In this study, many functional genes were detected in the uncontaminated samples that were not detected in the contaminated samples (Supplementary Table S3 and Supplementary Figure S10). These results suggest that oil spills can select against those populations containing these genes, 
or that specific members of the community have a selective advantage if they are capable of HC degradation and these grow to represent a greater proportion of the functional gene repertoire.

In conclusion, our results indicate that a variety of HC-degrading functional genes were enriched in response to oil contamination and associated environmental changes. Our results also imply that there is a great potential for in situ bioremediation of oil contaminants in the deep-seawater ecosystem, and such oil-degrading populations and associated microbial communities may have a significant role in determining the ultimate fates and consequences of the spilled oil. However, to further understand and evaluate the potential impacts of this unprecedented oil spill on the marine ecosystem structure and function, it is essential to launch an integrated and comprehensive monitoring program to track the dynamics and adaptive responses of microbial communities together with other physical and chemical analysis of tracing oil contaminants and their products.

\section{Acknowledgements}

We thank the Captain, crew and science teams aboard the R/V Ocean Veritas and R/V Brooks McCall. This work was part of ENIGMA, a Scientific Focus Area Program supported by the US Department of Energy, Office of Science, Office of Biological and Environmental Research, Genomics: GTL Foundational Science through Contract DE-AC02-05CH11231 between Lawrence Berkeley National Laboratory and the US Department of Energy. This study was also supported by University of Oklahoma Research Foundation, the National Key Science and Technology Project of China: Water Pollution Control and Treatment (No. 2008ZX07101-006), the Natural Science Foundation of Zhejiang Province (No. R5080124) and the National Key Technologies Research and Development Program of China during the 11th Five-Year Plan Period (No. 2006BAJ08B01).

\section{References}

Aitken CM, Jones DM, Larter SR. (2004). Anaerobic hydrocarbon biodegradation in deep subsurface oil reservoirs. Nature 431: 291-294.

Anderson M. (2001). A new method for non-parametric multivariate analysis of variance. Austral Ecol 26: $32-46$.

Barbeau K, Rue EL, Bruland KW, Butler A. (2001a). Photochemical cycling of iron in the surface ocean mediated by microbial iron(III)-binding ligands. Nature 413: 409-413.

Barbeau K, Zhang G, Live DH, Butler A. (2001b). Petrobactin, a photoreactive siderophore produced by the oil-degrading marine bacterium Marinobacter hydrocarbonoclasticus. J Am Chem Soc 124: 378-379.

Bordenave S, Goni-Urriza MS, Caumette P, Duran R. (2007). Effects of heavy fuel oil on the bacterial community structure of a pristine microbial mat. Appl Environ Microbiol 73: 6089-6097.

Camilli R, Reddy CM, Yoerger DR, Van Mooy BAS, Jakuba MV, Kinsey JC et al. (2010). Tracking hydrocarbon plume transport and biodegradation at Deepwater Horizon. Science 330: 201-204.

Cochran PK, Kellogg CA, Paul JH. (1998). Prophage induction of indigenous marine lysogenic bacteria by environmental pollutants. Mar Ecol Prog Ser 164: 125-133.

de Hoon MJ, Imoto S, Nolan J, Miyano S. (2004). Open source clustering software. Bioinformatics 20: 1453-1454.

Harayama S, Kasai Y, Hara A. (2004). Microbial communities in oil-contaminated seawater. Curr Opin Biotechnol 15: 205-214.

Hazen TC, Dubinsky EA, DeSantis TZ, Andersen GL, Piceno YM, Singh N et al. (2010). Deep-sea oil plume enriches indigenous oil-degrading bacteria. Science 330: 204-208.

He Z, Deng Y, Van Nostrand JD, Tu Q, Xu M, Hemme CL et al. (2010). GeoChip 3.0 as a high-throughput tool for analyzing microbial community composition, structure and functional activity. ISME J 4: 1167-1179.

Head IM, Jones DM, Larter SR. (2003). Biological activity in the deep subsurface and the origin of heavy oil. Nature 426: 344-352.

Head IM, Jones DM, Roling WFM. (2006). Marine microorganisms make a meal of oil. Nat Rev Micro 4: 173-182.

Jiang SC, Kellogg CA, Paul JH. (1998). Characterization of marine temperate phage-host systems isolated from Mamala Bay, Oahu, Hawaii. Appl Environ Microbiol 64: 535-542.

Jones DM, Head IM, Gray ND, Adams JJ, Rowan AK, Aitken CM et al. (2008). Crude-oil biodegradation via methanogenesis in subsurface petroleum reservoirs. Nature 451: 176-180.

Kerr R, Kintisch E, Stokstad E. (2010a). Will deepwater horizon set a new standard for catastrophe? Science 328: $674-675$.

Kerr RA, Kintisch E, Schenkman L, Stokstad E. (2010b). Five questions on the spill. Science 328: 962-963.

Kessler JD, Valentine DL, Redmond MC, Du MR, Chan EW, Mendes SD et al. (2011). A Persistent oxygen anomaly reveals the fate of spilled methane in the deep Gulf of Mexico. Science 331: 312-315.

Kniemeyer O, Musat F, Sievert SM, Knittel K, Wilkes H, Blumenberg $\mathrm{M}$ et al. (2007). Anaerobic oxidation of short-chain hydrocarbons by marine sulphatereducing bacteria. Nature 449: 898-901.

Kunapuli U, Lueders T, Meckenstock RU. (2007). The use of stable isotope probing to identify key iron-reducing microorganisms involved in anaerobic benzene degradation. ISME J 1: 643-653.

Larter S, Wilhelms A, Head I, Koopmans M, Aplin A, Di Primio R et al. (2003). The controls on the composition of biodegraded oils in the deep subsurface-part 1: biodegradation rates in petroleum reservoirs. Org Geochem 34: 601-613.

Luo Y, Hui D, Zhang D. (2006). Elevated $\mathrm{CO}_{2}$ stimulates net accumulations of carbon and nitrogen in land ecosystems: a meta-analysis. Ecology 87: 53-63.

Mascarelli A. (2010a). Extent of lingering Gulf oil plume revealed. Nature; doi: 10.1038/news.2010.1420. http:// www.nature.com/nature/archive/category.html?code= archive_news\&year $=2010 \&$ month $=08 \&$ page $=2$. 
Mascarelli A. (2010b). Deepwater horizon: after the oil. Nature 467: 22-24.

Meckenstock RU, Annweiler E, Michaelis W, Richnow HH, Schink B. (2000). Anaerobic naphthalene degradation by a sulfate-reducing enrichment culture. Appl Environ Microbiol 66: 2743-2747.

Operational Science Advisory Team (OSAT) (2010). Summary report for sub-sea and sub-surface oil and dispersant detection: sampling monitoring, 17 December 2010. http://www.restorethegulf.gov/release/2010/12/16/ data-analysis-and-findings.

Parales RE, Haddock JD. (2004). Biocatalytic degradation of pollutants. Curr Opin Biotechnol 15: 374-379.

Paul JH. (2008). Prophages in marine bacteria: dangerous molecular time bombs or the key to survival in the seas? ISME J 2: 579-589.

Ramette A, Tiedje J. (2007). Biogeography: an emerging cornerstone for understanding prokaryotic diversity, ecology, and evolution. Microb Ecol 53: 197-207.

Rojo F, Martínez JL. (2010). Oil Degraders as Pathogens. In: Timmis KN (ed). Handbook of Hydrocarbon and Lipid Microbiology. Springer: Berlin, Heidelberg, pp 3293-3303.

So CM, Phelps CD, Young LY. (2003). Anaerobic transformation of alkanes to fatty acids by a sulfate-reducing bacterium, strain Hxd3. Appl Environ Microbiol 69: 3892-3900.

The Federal Interagency Solutions Group (2010). Oil Budget Calculator Science and Engineering Team. Oil budget calculator deepwater horizon technical documentation. November 2010. http://www. restorethegulf.gov/sites/default/files/documents/pdf/ OilBudgetCalc_Full_HQ-Print_111110.pdf.

Valentine DL, Kessler JD, Redmond MC, Mendes SD, Heintz MB, Farwell C et al. (2010). Propane respiration jump-starts microbial response to a deep oil spill. Science 330: 208-211.

Widdel F, Rabus R. (2001). Anaerobic biodegradation of saturated and aromatic hydrocarbons. Curr Opin Biotechnol 12: 259-276.

Wu L, Liu X, Schadt CW, Zhou J. (2006). Microarraybased analysis of subnanogram quantities of microbial community DNAs by using whole-community genome amplification. Appl Environ Microbiol 72: 4931-4941.

Zhou J, Kang S, Schadt CW, Garten CT. (2008). Spatial scaling of functional gene diversity across various microbial taxa. Proc Natl Acad Sci USA 105: 7768-7773.

Supplementary Information accompanies the paper on The ISME Journal website (http://www.nature.com/ismej) 